\title{
KARAKTERISTIK GENETIK PADA FAMILI CERVIDAE (Cervus unicolor, Cervus timorensis, dan Axis kuhlii) BERDASARKAN 12SrRNA mtDNA
}

\author{
Wirdateti $^{*}$, Gono Semiadi*, Toshinao Okayama** \\ ${ }^{*}$ Bidang Zoologi, Puslit Biologi LIPI \\ ${ }^{* *}$ Biodiversity Conservation Project, JICA-LIPI \\ JI. Raya Cibinong KM 46, Cibinong-Jabar, 16911
}

\begin{abstract}
Genetic analysis from three species of Indonesia Cervidae (sambar deer, Cervus unicolor; rusa deer, Cervus timorensis; and Bawean deer, Axis kuhlii) was conducted to analyze their relationship. Tissues and blood from twelve sambar deer, one rusa deer and three Bawean deer were collected and analyzed for 12SrRNA using Primer forward (L1091) and reverse (H1478). The results indicated the amplication of mtDNA were 389 base nucleotide. There were 22 polimorphic sites, which were dominated by transition and gave 9 haplotypes that were 5 in sambar deer, 1 in rusa deer and 3 in Bawean deer.
\end{abstract}

Key words: Genetic, Cervus unicolor, Cervus timorensis, Axis kuhlii, 12SrRNA

\section{PENGANTAR}

Rusa Indonesia termasuk satwa yang dilindungi undang-undang tetapi sekaligus berpotensi sebagai sumber protein, sebagaimana dikembangkan di luar negeri (Semiadi 1993; Woodford \& Dunning 1992). Dari hasil pengamatan di luar negeri dan beberapa pengamatan awal di Indonesia menunjukkan rusa tropik mudah berkembang biak, sehingga satwa ini sangat potensial untuk dimanfaatkan sesuai dengan potensinya melalui program budidaya dan sekaligus ke arah domestikasi (Semiadi, 2002). Sebagai sumber daya alam, rusa mempunyai manfaat multi ganda baik sebagai sumber pangan, objek pariwisata, estetika, di samping sebagai sumber pangan.

Indonesia mempunyai empat jenis rusa yaitu Cervus unicolor (rusa sambar) yang mempunyai bobot badan terbesar sekitar 160-200 kg/ekor dengan dua anak jenis yaitu Cervus unicolor equinus (Sumatera) dan Cervus unicolor bookei (Kalimantan), Cervus timorensis (rusa timor) yang berbobot badan sekitar 45-155 kg/ekor dengan enam anak jenis, Axis kuhlii (rusa bawean) yang merupakan satwa endemik di Pulau Bawean dengan bobot badan 30-45 kg/ekor dan Muntiacus muncak (muncak) sebagai jenis rusa terkecil yang kita miliki dengan bobot badan tidak lebih dari 25 kg/ekor (Anderson, 1984). Secara morfologi ketiga rusa (sambar, timor, dan bawean) dibedakan dari ukuran tubuh, bobot tubuh, dan warna bulu, sedangkan Muntiacus muncak secara taksonomi (morfologi) jauh berbeda dengan ketiga jenis rusa dari Cervidae.

Pencirian satwa ini secara genetik dalam usaha penentuan karakteristik, terutama pada rusa sambar dan timor baik di penangkaran maupun di alam sangatlah penting, karena introduce spesies ke suatu daerah yang tidak terkendali baik oleh alam maupun manusia akan mempengaruhi karakter spesifik dari masing-masing jenis terlebih apabila proses hibridisasi antar jenis dimungkinkan terjadi secara alami. Selain itu saat ini masih belum banyak diketahui karakteristik masing-masing spesies ini guna penentuan kondisi genetiknya dalam usaha pemanfaatan satwa ini sebagai komoditi alternatif di dalam bidang peternakan. Untuk itu dilakukan kajian karakteristik rusa Indonesia berdasarkan gen 12SrRNA mtDNA. Gen 12SrRNA adalah salah satu daerah coding dari 37 gen pada DNA mitokondria (mtDNA). Daerah mitokondria dikenal mengalami perubahan cepat dalam evolusi. Analisis restriksi dari mtDNA mamalia yang berhubungan dekat menunjukkan bahwa genom ini mempunyai laju evolusi yang lebih tinggi dari pada DNA inti (Brown et al., 1985; Kocher et al., 1989). Di samping itu DNA mitokondria merupakan alat yang kuat dalam mempelajari evolusi hewan dan juga banyak digunakan untuk analisis struktur populasi, aliran gen, dan filogeni (Moritz et al., 1974).

\section{BAHAN DAN CARA KERJA}

Lokasi sampel: Sampel diperoleh dari Kabupaten Penajam Paser Utara, Kalimantan Timur untuk rusa sambar; Kabupaten Kupang, Pulau Timor untuk rusa timor; dan Kabupaten Pasuruan, Jawa Timur untuk rusa bawean. Sampel terdiri atas darah, daging, hati, sesuai dengan Tabel 1. Sampel asal rusa sambar berupa jaringan daging dan hati diperoleh dari cuplikan jaringan yang dibeli dari pasar 
tradisional. Pada sampel yang berupa darah diperoleh dari darah yang ada di penangkaran Dinas Peternakan TK. I di desa Api-Api, Kecamatan Waru, Kabupaten Penajam Paser Utara, melalui pengambilan lewat vena jugularis dan tanpa obat bius. Sampel asal rusa timor dan rusa bawean diperoleh dari satwa di penangkaran (Kebun Binatang Surabaya untuk sampel rusa Bawean dan Camplong, Kupang untuk sampel rusa timor). Larutan preservasi yang dipakai untuk jaringan daging dan hati berupa etanol absolut, dan pada darah bervariasi antara EDTA dan etanol absolut.

\section{Ektsraksi DNA}

Total DNA diekstraksi dari darah dan jaringan dengan menggunakan metode Sambruk et al. (1989), dengan phenol-chloroform dan presipitasi dengan etanol absolut. Kemudian DNA dilarutkan dalam larutan TE dan disimpan dalam suhu dingin $\left(4-20^{\circ} \mathrm{C}\right)$ sampai digunakan.

\section{Amplifikasi dan Sekuensing}

Untuk mendapatkan gen 12S rRNA mtDNA, total DNA diamplifikasi dengan menggunakan Polymerase Chain Reaction (PCR). Amplifikasi pada daerah gen 12 S rRNA, menggunakan primer H1478 dan L1091 (Kocher et al., 1989) dalam $50 \mu \mathrm{l}$ volume reaksi terdiri atas $5 \mu \mathrm{l}$ buffer $10 \times$, $4 \mu \mathrm{l} 10 \mathrm{mM}$ dNTP mix, $5 \mu \mathrm{l}$ 2pm primer, $1 \mu \mathrm{l} 1.25 \mathrm{U}$ Taq Polymerase, 1-2 $\mu \mathrm{l}$ DNA template, dan $29 \mu \mathrm{l}$ MQ. Amplifikasi menggunakan mesin Thermal Cycle 9600 Perkin Elmer. Kondisi PCR $95^{\circ} \mathrm{C}, 5 \mathrm{~min} ; 40$ cycles $\left(95^{\circ} \mathrm{C}\right.$ selama 30 detik, $55^{\circ} \mathrm{C}$ selama 30 detik, $72^{\circ} \mathrm{C}$ selama 60 det.), Hasil amplifikasi dielektroforesis pada $1 \%$ Seakem agarose gel di dalam $1 \times$ TAE buffer dan diwarnai dengan ethidium bromide. PCR product dipurifikasi dengan MicroSpin TM S-400 HR Colums (Amersham).

Seluruh sekuen diperoleh dari DNA double-strand dengan menggunakan Thermosequenase dye primer cycle sequensing kit (Amersham) pada ALF express DNA sequencer.

\section{Analisis data}

Penjajaran sekuen nucleotide menggunakan Clustal X (Jeanmougin et al., 1998). Untuk menghitung haplotipe diversity (h) mengikuti Li \& Graur (1991). Untuk menggambarkan pohon filogeni dengan menggunakan Program PHYLIP NEIGHBOR (Felsenstein, 1989).

\section{HASIL}

Hasil sekuen dari 12 rusa sambar, 1 rusa timor, dan 3 rusa bawean dengan menggunakan primer Cy5L1091 adalah sepanjang 389base pair (bp) nukleotida (Gambar 1).
Pada jajaran sekuen terdapat 22 variasi mutasi, mutasi terjadi karena kejadian transisi dan tranversi basa. Pada hasil sekuen ini mutasi didominasi oleh kejadian transisi dari G-A, C-T dan sebaliknya $(72,73 \%)$ yaitu pada urutan basa ke-11, 50, 67, 76, 79, 118, 119, 147, 155, 187, 236, 285, 319, 354, 356, dan basa ke 389, sedangkan kejadian tranversi dari G-T, A-T, dan A-C terdapat pada sekuen ke-90, 186, dan 219 (13,64\%). Di samping itu juga terjadi perubahan basa akibat insersi dan delesi basa pada urutan basa ke-5, 190, dan 388 (13,64\%). Mutasi atau substitusi basa pada ketiga jenis rusa tersebut memberikan 8 haplotipe (SB1, SB2, SB3, SB4, SB5, TM1, BW1 dan BW2) (Tabel 2). Haplotipe SB1, SB2, SB3, SB4, dan SB5) adalah merupakan sebaran haplotipe atau karakteristik dari populasi rusa sambar di desa Api-Api, Kaltim. Tingkat keragaman haplotipe ( $h$ ) pada populasi rusa sambar di daerah tersebut menunjukkan cukup tinggi (57,61\%). Perbedaan (variasi haplotipe) yang cukup tinggi pada rusa sambar disebabkan perubahan pada urutan ke-389 dari A-G dari individu yang berasal dari Babulu dan kota Samarinda. Selain itu juga karena adanya delesi basa Guanin pada posisi ke-5 dan ke-388 dari individu yang berasal dari Babulu, dan juga adanya insersi basa Guanin pada posisi ke-190 dari individu yang berasal dari desa Api-Api, Kabupaten Penajam. Individu lain yang berasal dari Api-Api juga mengalami perubahan basa adalah pada posisi basa ke-187, 236, dan 389. Apabila tidak adanya gap (insersi dan delesi) basa, atau kejadian insersi dan delesi basa pada urutan sekuen ini diabaikan, maka keragaman rusa sambar rendah, meskipun diperoleh dari lokasi yang berbeda (Tabel 2).

Sementara pada rusa bawean dari 3 individu yang dianalisis memberikan 2 penciri (haplotipe) yaitu BW1 dan BW2. Perbedaan nukleotide pada jenis ini terjadinya delesi basa Timin (T) pada urutan basa ke-5. Apabila kejadian delesi basa ini diabaikan, maka ketiga individu rusa bawean ini menunjukkan populasi monomorf. Untuk rusa timor hanya 1 individu memberikan penciri tersendiri yaitu haplotipe TM1.

\section{PEMBAHASAN DAN KESIMPULAN}

Dari perbandingan pasangan basa dari ketiga sekuen rusa tersebut menunjukkan bahwa antara rusa sambar dan rusa timor memperlihatkan kemiripan nukleotide yang lebih tinggi dalam hal ini hanya terdapat 2 mutasi basa secara transisi, yaitu dari G-A, pada posisi basa ke-236 dan 285 (Tabel 2). Tingkat kekerabatan yang lebih jauh adalah antara rusa timor dengan rusa bawean, yaitu terdapat 16 mutasi basa atau sekitar $4,1 \%$, sedangkan antara rusa 
sambar dengan rusa bawean terdapat 18 mutasi basa atau sekitar 4,9\% (Gambar 1, Tabel 2). Dari 22 situs bervariasi dalam 388 sekuen basa terdapat 3 transversi yang menunjukkan ratio transisi/transversi lebih kurang 5 : 1 . Ratio nilai ini menunjukkan kejadian yang normal pada mamalia, seperti dilaporkan Irwin et al., (1991), bahwa perbandingan kejadian transisi/transversi pada sekuen basa mamalia yang normal adalah mendekati 10. Posisi perubahan basa dari kedua spesies tersebut dengan tiga individu rusa bawean adalah pada situs yang sama. Dari hasil penelitian terhadap rusa sambar dilaporkan, bahwa perbandingan pasangan sekuen antara Cervus unicolor (rusa sambar) dengan Muntiacus muncak (muncak) pada daerah 12S rRNA dan 16S rRNA sepanjang 962 sekuen nukleotida (Cervus/Muntiacus) ditemukan 23 mutasi, dan yang menunjukkan kesamaan sekuen mencapai 98,3\% (Miyamoto et al., 1990). Sedangkan dalam penelitian ini kesamaan sekuen C. unicolor/C. timorensis sebesar 99,48\% yang menunjukkan kemiripan yang lebih tinggi; C. unicolor/A. kuhlii sebesar 95,37\%; C. timorensis/ A. kuhlii sebesar 95,88\%. Dari hasil penelitian ini menunjukkan bahwa rusa Axis kuhlii memberikan perbedaan nukleotida yang lebih tinggi di antara 2 jenis cervidae lainnya. Hasil pengamatan pada runutan nucleotida rusa bawean menunjukkan adanya indikasi proses laju evolusi dari perubahan basa secara transisi maupun transversi. Hal ini tampaknya sesuai dengan proses evolusi di alam di mana Pulau Bawean telah mengalami isolasi dari daratan utama di zaman Pelitoceen. Asal usul rusa Bawean dan bagaimana caranya mencapai pulau Bawean tidak diketahui dengan pasti. Diduga bahwa nenek moyang rusa bawean terpisah dari kerabatnya sekitar masa diuvial, ketika daratan Sunda Shelf terpisah akibat naiknya permukaan laut (Von Koeningswald dalam Bemmel, 1953).

Dari ketiga spesies ini menunjukkan adanya variasi laju evolusi pada situs yang berbeda dari sekuen nukleotida. Churchill (1997) dalam Cook et al. (1999), menerangkan bahwa metode untuk menghitung variasi laju evolusi pada situs berbeda dari sekuen nukleotida dengan menggunakan model Markov, menunjukkan bahwa laju evolusi pada situs berbeda dari sekuen nukleotida adalah tidak sama.

Pohon filogeni yang digambarkan dengan menggunakan matric distance dari program PHYLIP NEIGHBOR menunjukkan hubungan yang dekat antara
Cervus unicolor dengan Cervus timorensis, akan tetapi menunjukkan perbedaan signifikan dengan Axis kuhlii (Gambar 2). Dari pohon filogenetik ini menunjukkan, bahwa rusa bawean adalah jenis rusa termuda atau termodern dari 3 jenis rusa yang ada di Indonesia, di mana rusa ini hanya terdapat di Pulau Bawean, Jawa Timur. Dari hasil analisis filogenetik yang dilakukan Randi et al. (2001) menunjukkan juga bahwa hubungan kekerabatan antara $C$. unicolor dengan $C$. timorensis sangat dekat (bootstrap 85\%), berada dalam satu clade, bahkan kedua species ini mempunyai tandem repeat yang cukup tinggi pada daerah control region mtDNA. Daerah control region mtDNA diketahui mengalami laju substitusi yang lebih tinggi dari daerah mtDNA lainnya, di mana daerah ini merupakan awal dari transkripsi gen. Akan tetapi bagian central dari daerah ini menunjukkan adanya kesamaan nukleotida antar spesies (Mignotte et al., 1986).

Satu haplotipe dari rusa sambar yaitu SB5 (individu dari Api-Api), menunjukkan lebih dekat dengan timor dan terpisah dengan kelompok populasi sambar lainnya. Haplotipe ini mengalami perubahan basa dengan sambar lainnya pada posisi basa ke-187 dan 236. Adanya pemisahan seekor rusa sambar yang satu kelompok dengan rusa timor, mungkin terjadi mengingat di saat konflik Timor-Timur tahun 1980-an, banyak tentara yang kembali dari tugas membawa anak rusa timor dan mengembangkannya di sekitar Kabupaten Penajam Paser Utara. Pada beberapa rusa yang dipelihara ini tidak sedikit dilaporkan yang kemudian menghilang di hutan sekitar yang kemungkinan highbreed dengan rusa sambar (Erik Nursyamdani, komunikasi pribadi dengan G. Semiadi)

Hasil penelitian menunjukkan, bahwa panjang gen 12SrRNA mtDNA yang teramplifikasi dengan menggunakan primer L1091 dan H1478 adalah sekitar 389 bp nukleotida. Dari 389 bp nukleotida ditemukan sebanyak 22 variasi basa pada situs yang berbeda. Mutasi basa (variasi basa) tersebut didominasi dengan kejadian transisi yaitu dari Adenin (A) ke Guanin (G); Timin (T) ke Citosin (C) dan sebaliknya. Mutasi basa ini memberikan 8 haplotipe yaitu 5 haplotipe pada populasi rusa sambar; 2 haplotipe pada rusa bawean dan 1 haplotipe pada rusa timor. Tingkat kekerabatan di antara 3 spesies rusa ini menunjukkan, bahwa rusa sambar dan timor menunjukkan jarak genetik yang lebih dekat dibandingkan dengan rusa bawean. 
Tabel 1. Asal rusa, bagian yang diekstrak, lokasi sampel, dan preservasi sampel

\begin{tabular}{|c|c|c|c|c|}
\hline No. & Kode & Jaringan & Lokasi & Preservasi \\
\hline \multicolumn{5}{|c|}{ Rusa sambar } \\
\hline 1. & Cu010 & Daging & Babulu $\quad(B B)$ & Etanol 99\% \\
\hline 2. & Cu10 & Daging & Babulu (BB) & Etanol 99\% \\
\hline 3. & Cu09 & Darah & Api-api (AP) & Etanol 99\% \\
\hline 4. & Cu03 & Daging & Waru (WR) & Etanol 99\% \\
\hline 5. & Cu06 & Daging & Babulu (BB) & Etanol 99\% \\
\hline 6. & Cu02 & Daging & Petung (PT) & Etanol $99 \%$ \\
\hline 7. & Cu19 & Darah & Api-api (AP) & Etanol 99\% \\
\hline 8. & Cu34 & Daging & Samarinda (SD) & Kering, grinding \\
\hline 9. & Cu36 & Daging & Samarinda (SD) & kering, grinding \\
\hline 10. & Cu38 & Daging & Samarinda (SD) & Kering, grinding \\
\hline 11. & Cu23 & Daging & Samarinda (SD) & Kering, grinding \\
\hline 12. & Cu42 & Daging & Samarinda (SD) & Kering, grinding \\
\hline \multicolumn{5}{|c|}{ Rusa Timor } \\
\hline 1. & CT28 & Hati & Champlong (CL) & Etanol 99\% \\
\hline \multicolumn{5}{|c|}{ Rusa Bawean } \\
\hline 1. & AK44 & Daging & Penangkar & Beku langsung \\
\hline 2. & AK2 & Darah & Penangkar & EDTA \\
\hline 3. & $A K$ & Darah & Penangkar & EDTA \\
\hline
\end{tabular}

Tabel 2. Posisi polimorphic antara haplotipe rusa sambar.*

\begin{tabular}{|c|c|c|c|c|c|c|c|c|c|c|c|c|c|c|c|c|c|c|c|c|c|c|}
\hline $\begin{array}{l}\text { Haplo } \\
\text { tipe }\end{array}$ & 5 & 11 & 50 & 67 & 76 & 79 & 90 & 118 & 119 & 147 & 155 & 186 & 187 & 190 & 219 & 236 & 285 & 319 & 354 & 356 & 388 & 389 \\
\hline SB1 & - & $A$ & $G$ & $\mathrm{G}$ & $\mathrm{G}$ & $\mathrm{G}$ & $G$ & $G$ & $T$ & $T$ & $A$ & $A$ & $\mathrm{G}$ & - & $T$ & $A$ & $G$ & $A$ & $C$ & $C$ & $G$ & $A$ \\
\hline SB2 & - & $\mathrm{G}$ & . & . & . & . & . & . & . & . & . & . & . & 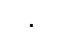 & . & . & . & . & . & . & - & \\
\hline SB3 & $\mathrm{T}$ & . & . & . & . & . & . & . & . & . & . & . & . & $\mathrm{G}$ & . & . & . & . & . & . & . & $\mathrm{G}$ \\
\hline SB4 & $\mathrm{T}$ &. &. & . &. &. & . & . & . & . & . & . & 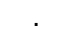 & & . & . & . & . & . & . & . & $\mathrm{G}$ \\
\hline SB5 & $\mathrm{T}$ & . & . & . & . & . & . & . & . & . & 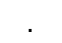 & . & A & G & . & G & . & . & . & . & . & $\mathrm{G}$ \\
\hline TM1 & $\mathrm{T}$ & . &. & . & . & . & . & . & . & . & . & . & . & 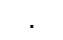 & . & G & A & . & . & . & . & $\mathrm{G}$ \\
\hline BW1 & $\mathrm{T}$ & . & A & $A$ & $A$ & A & $\mathrm{T}$ & A & C & C & G & $\mathrm{T}$ & A & G & A & G & A & G & $\mathrm{T}$ & $\mathrm{T}$ & . & $\mathrm{G}$ \\
\hline BW2 & - & . & A & $A$ & $A$ & $A$ & $\mathrm{~T}$ & A & C & C & $\mathrm{G}$ & $\mathrm{T}$ & A & G & A & G & A & G & $\mathrm{T}$ & $\mathrm{T}$ & . & $\mathrm{G}$ \\
\hline
\end{tabular}

Keterangan: * Titik menunjukkan basa yang sama dengan sekuen pertama (urutan pertama) 
CLUSTAL X (1.8) multiple sequence alignment

CU34SD -CTAAT-CAACTAAGCACTCTATTCTTAGTTTACTGCTAAATCCTCCTTTGGTTATTAAT CU010BB --TAAT-CAACTGAGCACTCTATTCTTAGTTTACTGCTAAATCCTCCTTTGGTTATTAAT CU19AP -CTAATTCAACTAAGCACTCTATTCTTAGTTTACTGCTAAATCCTCCTTTGGTTATTAAT CU38SD -TAATTCAACTAAGCACTCTATTCTTAGTTTACTGCTAAATCCTCCTTTGGTTATTAAT CU06BB CU02PT CU03WR CU36SD CU40SD CU10BB CT23YG CU09AP CT28BL AK2/15 AK AK44BW --TAATTCAACTAAGCACTCTATTCTTAGTTTACTGCTAAATCCTCCTTTGGTTATTAAT --TAATTCAACTAAGCACTCTATTCTTAGTTTACTGCTAAATCCTCCTTTGGTTATTAAT --TAATTCAACTAAGCACTCTATTCTTAGTTTACTGCTAAATCCTCCTTTGGTTATTAAT -CTAATTAAACTAAGCACTCTATTCTTAGTTTACTGCTAAATCCTCCTTTGGTTATTAAT -CTAATTCAACTAAGCACTCTATTCTTAGTTTACTGCTAAATCCTCCTTTGGTTATTAAT --TAATTCAACTAAGCACTCTATTCTTAGTTTACTGCTAAATCCTCCTTTGGTTATTAAT --TAATTCAACTAAGCACTCTATTCTTAGTTTACTGCTAAATCCTCCTTTGGTTATTAAT --TAATTCAACTAAGCACTCTATTCTTAGTTTACTGCTAAATCCTCCTTTGGTTATTAAT --TAATTCAACTAAGCACTCTATTCTTAGTTTACTGCTAAATCCTCCTTTGGTTATTAAT GCTAATTCAACTAAGCACTCTATTCTTAGTTTACTGCTAAATCCTCCTTTGATTATTAAT --TAATTCAACTAAGCACTCTATTCTTAGTTTACTGCTAAATCCTCCTTTGATTATTAAT --TAAT-CAACTAAGCACTCTATTCTTAGTTTACTGCTAAATCCTCCTTTGATTATTAAT **** $\quad * * * * \quad * * * * * * * * * * * * * * * * * * * * * * * * * * * * * * * * * * * * * * * * * * * * * * * * * * \quad * * * * * * * *$

CU34SD CU010BB CU19AP CU38SD CU06BB CU02PT CU03WR CU36SD CU40SD CU10BB CT23YG CU09AP CT28BL AK2/15 AK AK44BW

CU34SD CU010BB CU19AP CU38SD CU06BB CU02PT CU03WR CU36SD CU40SD CU10BB CT23YG CU09AP CT28BL AK2/15 AK AK44BW
TTCATAATGACTTTCGTGTTGGATTTTCTTAGATTAGAAAATGTAGCCCATTTCTTTCCG TTCATAATGACTTTCGTGTTGGATTTTCTTAGATTAGAAAATGTAGCCCATTTCTTTCCG TTCATAATGACTTTCGTGTTGGATTTTCTTAGATTAGAAAATGTAGCCCATTTCTTTCCG TTCATAATGACTTTCGTGTTGGATTTTCTTAGATTAGAAAATGTAGCCCATTTCTTTCCG TTCATAATGACTTTCGTGTTGGATTTTCTTAGATTAGAAAATGTAGCCCATTTCTTTCCG TTCATAATGACTTTCGTGTTGGATTTTCTTAGATTAGAAAATGTAGCCCATTTCTTTCCG TTCATAATGACTTTCGTGTTGGATTTTCTTAGATTAGAAAATGTAGCCCATTTCTTTCCG TTCATAATGACTTTCGTGTTGGATTTTCTTAGATTAGAAAATGTAGCCCATTTCTTTCCG TTCATAATGACTTTCGTGTTGGATTTTCTTAGATTAGAAAATGTAGCCCATTTCTTTCCG TTCATAATGACTTTCGTGTTGGATTTTCTTAGATTAGAAAATGTAGCCCATTTCTTTCCG TTCATAATGACTTTCGTGTTGGATTTTCTTAGATTAGAAAATGTAGCCCATTTCTTTCCG TTCATAATGACTTTCGTGTTGGATTTTCTTAGATTAGAAAATGTAGCCCATTTCTTTCCG TTCATAATAACTTTCGTGTTGGATTTTCTTAGATTAGAAAATGTAGCCCATTTCTTTCCG TTCATAATAACTTTCGTATTAGATTTTCTTATATTAGAAAATGTAGCCCATTTCTTTCCA TTCATAATAACTTTCGTATTAGATTTTCTTATATTAGAAAATGTAGCCCATTTCTTTCCA TTCATAATAACTTTCGTATTAGATTTTCTTATATTAGAAAATGTAGCCCATTTCTTTCCA

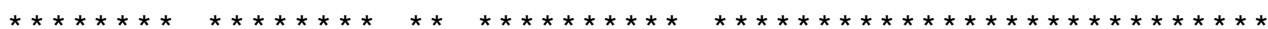

TTCCATAGGTTACACCTTGACCTAACGTTTTTATGTATTATGATTGTGCTTACTTTTGTA TTCCATAGGTTACACCTTGACCTAACGTTTTTATGTATTATGATTGTGCTTACTTTTGTA TTCCATAGGTTACACCTTGACCTAACGTTTTTATGTATTATGATTGTGCTTACTTTTGTA TTCCATAGGTTACACCTTGACCTAACGTTTTTATGTATTATGATTGTGCTTACTTTTGTA TTCCATAGGTTACACCTTGACCTAACGTTTTTATGTATTATGATTGTGCTTACTTTTGTA TTCCATAGGTTACACCTTGACCTAACGTTTTTATGTATTATGATTGTGCTTACTTTTGTA TTCCATAGGTTACACCTTGACCTAACGTTTTTATGTATTATGATTGTGCTTACTTTTGTA TTCCATAGGTTACACCTTGACCTAACGTTTTTATGTATTATGATTGTGCTTACTTTTGTA TTCCATAGGTTACACCTTGACCTAACGTTTTTATGTATTATGATTGTGCTTACTTTTGTA TTCCATAGGTTACACCTTGACCTAACGTTTTTATGTATTATGATTGTGCTTACTTTTGTA TTCCATAGGTTACACCTTGACCTAACGTTTTTATGTATTATGATTGTGCTTACTTTTGTA TTCCATAGGTTACACCTTGACCTAACGTTTTTATGTATTATGATTGTGCTTACTTTTGTA TTCCATAGGTTACACCTTGACCTAACGTTTTTATGTATTATGATTGTGCTTACTTTTGTA CTCCATAGGTTACACCTTGACCTAACGTCTTTATGTGTTATGATTGTGCTTACTTTTGTA CTCCATAGGTTACACCTTGACCTAACGTCTTTATGTGTTATGATTGTGCTTACTTTTGTA CTCCATAGGTTACACCTTGACCTAACGTCTTTATGTGTTATGATTGTGCTTACTTTTGTA 
CU34SD CU010BB CU19AP CU38SD CU06BB CU02PT CU03WR CU36SD CU40SD CU10BB CT23YG CU09AP CT28BL AK2/15 AK AK44BW

CU34SD CU010BB CU19AP CU38SD CU06BB CU02PT CU03WR CU36SD CU40SD CU10BB CT23YG CU09AP CT28BL AK2/15 AK AK44BW

CU34SD CU010BB CU19AP CU38SD CU06BB CU02PT

CU03WR CU36SD CU40SD CU10BB CT23YG CU09AP CT28BL AK2/15 AK AK44BW
CCTTTTTAGGG-TTTGCTGAAGATGGCGGTATATAGACTGTATTAGCAAGGAATGGTAAG CCTTTTTAGGG-TTTGCTGAAGATGGCGGTATATAGACTGTATTAGCAAGGAATGGTAAG CCTTTTTAGGGGTTTGCTGAAGATGGCGGTATATAGACTGTATTAGCAAGGAATGGTAAG CCTTTTTAGGG-TTTGCTGAAGATGGCGGTATATAGACTGTATTAGCAAGGAATGGTAAG CCTTTTTAGGG-TTTGCTGAAGATGGCGGTATATAGACTGTATTAGCAAGGAATGGTAAG CCTTTTTAGGG-TTTGCTGAAGATGGCGGTATATAGACTGTATTAGCAAGGAATGGTAAG CCTTTTTAGGG-TTTGCTGAAGATGGCGGTATATAGACTGTATTAGCAAGGAATGGTAAG CCTTTTTAGGG-TTTGCTGAAGATGGCGGTATATAGACTGTATTAGCAAGGAATGGTAAG CCTTTTTAGGG-TTTGCTGAAGATGGCGGTATATAGACTGTATTAGCAAGGAATGGTAAG CCTTTTTAGGG-TTTGCTGAAGATGGCGGTATATAGACTGTATTAGCAAGGAATGGTAAG CCTTTTTAGGG-TTTGCTGAAGATGGCGGTATATAGACTGTATTAGCAAGGAATGGTAAG CCTTTTTTAGGGTTTGCTGAAGATGGCGGTATATAGACTGTATTAGCAAGGAATGGTGAG CCTTTTTAGGG-TTTGCTGAAGATGGCGGTATATAGACTGTATTAGCAAGGAATGGTGAG CCTTTTTTAGGGTTTGCTGAAGATGGCGGTATATAGACTGAATTAGCAAGGAATGGTGAG CСTTTTTTAGGGTTTGCTGAAGATGGCGGTATATAGACTGAATTAGCAAGGAATGGTGAG CCTTTTTTAGGGTTTGCTGAAGATGGCGGTATATAGACTGAATTAGCAAGGAATGGTGAG

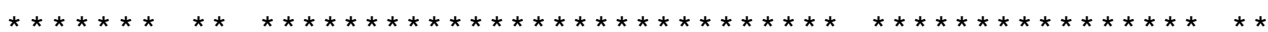

GTTTATCGGGGTTTATCGATTATAGAACAGGCTCCTCTAGAAGGGTGTAAAGCACCGCCA GTTTATCGGGGTTTATCGATTATAGAACAGGCTCCTCTAGAAGGGTGTAAAGCACCGCCA GTTTATCGGGGTTTATCGATTATAGAACAGGCTCCTCTAGAAGGGTGTAAAGCACCGCCA GTTTATCGGGGTTTATCGATTATAGAACAGGCTCCTCTAGAAGGGTGTAAAGCACCGCCA GTTTATCGGGGTTTATCGATTATAGAACAGGCTCCTCTAGAAGGGTGTAAAGCACCGCCA GTTTATCGGGGTTTATCGATTATAGAACAGGCTCCTCTAGAAGGGTGTAAAGCACCGCCA GTTTATCGGGGTTTATCGATTATAGAACAGGCTCCTCTAGAAGGGTGTAAAGCACCGCCA GTTTATCGGGGTTTATCGATTATAGAACAGGCTCCTCTAGAAGGGTGTAAAGCACCGCCA GTTTATCGGGGTTTATCGATTATAGAACAGGCTCCTCTAGAAGGGTGTAAAGCACCGCCA GTTTATCGGGGTTTATCGATTATAGAACAGGCTCCTCTAGAAGGGTGTAAAGCACCGCCA GTTTATCGGGGTTTATCGATTATAGAACAGGCTCCTCTAGAAGGGTGTAAAGCACCGCCA GTTTATCGGGGTTTATCGATTATAGAACAGGCTCCTCTAGAAGGGTGTAAAGCACCGCCA GTTTATCGGGGTTTATCGATTATAGAACAGGCTCCTCTAGAAGGGTATAAAGCACCGCCA GTTTATCGGGGTTTATCGATTATAGAACAGGCTCCTCTAGAAGGGTATAAAG CACCGCCA GTTTATCGGGGTTTATCGATTATAGAACAGGCTCCTCTAGAAGGGTATAAAGCAC CGCCA GTTTATCGGGGTTTATCGATTATAGAACAGGCTCCTCTAGAAGGGTATAAAGCACCGCCA

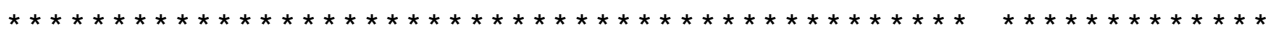

AGTCCTTTGAGTTTTAAGCTATTGCCGGTAGTACTCTGGCGAATAGTTTTGTTTACACAA AGTCCTTTGAGTTTTAAGCTATTGCCGGTAGTACTCTGGCGAATAGTTTTGTTTACACAA AGTCCTTTGAGTTTTAAGCTATTGCCGGTAGTACTCTGGCGAATAGTTTTGTTTACACAA AGTCCTTTGAGTTTTAAGCTATTGCCGGTAGTACTCTGGCGAATAGTTTTGTTTACACAA AGTCCTTTGAGTTTTAAGCTATTGCCGGTAGTACTCTGGCGAATAGTTTTGTTTACACAA AGTCCTTTGAGTTTTAAGCTATTGCCGGTAGTACTCTGGCGAATAGTTTTGTTTACACAA AGTCCTTTGAGTTTTAAGCTATTGCCGGTAGTACTCTGGCGAATAGTTTTGTTTACACAA AGTCCTTTGAGTTTTAAGCTATTGCCGGTAGTACTCTGGCGAATAGTTTTGTTTACACAA AGTCCTTTGAGTTTTAAGCTATTGCCGGTAGTACTCTGGCGAATAGTTTTGTTTACACAA AGTCCTTTGAGTTTTAAGCTATTGCCGGTAGTACTCTGGCGAATAGTTTTGTTTACACAA AGTCCTTTGAGTTTTAAGCTATTGCCGGTAGTACTCTGGCGAATAGTTTTGTTTACACAA AGTCCTTTGAGTTTTAAGCTATTGCCGGTAGTACTCTGGCGAATAGTTTTGTTTACACAA AGTCCTTTGAGTTTTAAGCTATTGCCGGTAGTACTCTGGCGAATAGTTTTGTTTACACAA AGTCCTTTGAGTTTTAAGCTGTTGCCGGTAGTACTCTGGCGAATAGTTTTGTTTATATAA AGTCCTTTGAGTTTTAAGCTGTTGCCGGTAGTACTCTGGCGAATAGTTTTGTTTATATAA AGTCCTTTGAGTTTTAAGCTGTTGCCGGTAGTACTCTGGCGAATAGTTTTGTTTATATAA

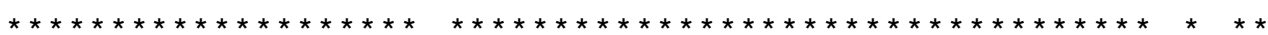




\begin{tabular}{|c|c|c|c|c|c|c|c|c|c|c|c|c|c|c|c|c|c|c|c|c|c|c|c|c|c|c|c|c|c|c|}
\hline CU34SD & C & $\mathrm{T}$ & $A$ & $\mathrm{~T}$ & $\mathrm{~T}$ & $\mathrm{~T}$ & $\mathrm{G}$ & $\mathrm{T}$ & $\mathrm{G}$ & $\mathrm{T}$ & $\mathrm{T}$ & $\mathrm{T}$ & $A$ & $A$ & $\mathrm{G}$ & $\mathrm{G}$ & C & $\mathrm{T}$ & A & $\mathrm{G}$ & $G$ & C & A & $\mathrm{T}$ & A & G & $\mathrm{T}$ & $\mathrm{G}$ & $A$ & G \\
\hline CU010BB & C & $T$ & A & $\mathrm{T}$ & $\mathrm{T}$ & $\mathrm{T}$ & $\mathrm{G}$ & $\mathrm{T}$ & G & $\mathrm{T}$ & $\mathrm{T}$ & $\mathrm{T}$ & A & A & $\mathrm{G}$ & G & C & $T$ & $A$ & G & G & C & A & $\mathrm{T}$ & A & $\mathrm{G}$ & $\mathrm{T}$ & - & $A$ & \\
\hline CU19AP & C & $\mathrm{T}$ & A & $\mathrm{T}$ & $\mathrm{T}$ & $\mathrm{T}$ & $\mathrm{G}$ & $\mathrm{T}$ & $\mathrm{G}$ & $\mathrm{T}$ & $\mathrm{T}$ & $\mathrm{T}$ & $A$ & $A$ & $\mathrm{G}$ & G & C & $\mathrm{T}$ & A & G & $\mathrm{G}$ & C & A & $\mathrm{T}$ & A & G & $\mathrm{T}$ & $\mathrm{G}$ & $\mathrm{G}$ & \\
\hline CU38SD & C & $\mathrm{T}$ & A & $\mathrm{T}$ & $\mathrm{T}$ & $T$ & $G$ & $\mathrm{~T}$ & $G$ & $\mathrm{~T}$ & $\mathrm{~T}$ & $\mathrm{~T}$ & $A$ & $A$ & $G$ & $G$ & C & $\mathrm{T}$ & A & $G$ & $\mathrm{G}$ & C & A & $\mathrm{T}$ & A & $\mathrm{G}$ & $\mathrm{T}$ & G & $G$ & \\
\hline CU06BB & C & $\mathrm{T}$ & A & $\mathrm{T}$ & $\mathrm{T}$ & $T$ & $\mathrm{G}$ & $\mathrm{T}$ & G & $\mathrm{T}$ & $\mathrm{T}$ & $T$ & A & A & G & $\mathrm{G}$ & C & $\mathrm{T}$ & A & $\mathrm{G}$ & $\mathrm{G}$ & C & A & $\mathrm{T}$ & A & $\mathrm{G}$ & $\mathrm{T}$ & G & $\mathrm{G}$ & \\
\hline CU02PT & C & $\mathrm{T}$ & A & $\mathrm{T}$ & $\mathrm{T}$ & $T$ & $G$ & $\mathrm{~T}$ & $\mathrm{G}$ & $\mathrm{T}$ & $\mathrm{T}$ & $\mathrm{T}$ & $A$ & $A$ & $\mathrm{G}$ & $\mathrm{G}$ & C & $\mathrm{T}$ & $A$ & $\mathrm{G}$ & $\mathrm{G}$ & C & $A$ & $\mathrm{~T}$ & A & $\mathrm{G}$ & $\mathrm{T}$ & $\mathrm{G}$ & $\mathrm{G}$ & \\
\hline CU03WR & C & $\mathrm{T}$ & A & $\mathrm{T}$ & $\mathrm{T}$ & $\mathrm{T}$ & $\mathrm{G}$ & $\mathrm{T}$ & $\mathrm{G}$ & $\mathrm{T}$ & $\mathrm{T}$ & $\mathrm{T}$ & $A$ & $A$ & G & G & C & $\mathrm{T}$ & A & G & $\mathrm{G}$ & C & A & $\mathrm{T}$ & A & $\mathrm{G}$ & $\mathrm{T}$ & G & $\mathrm{G}$ & \\
\hline CU36SD & C & $\mathrm{T}$ & A & $\mathrm{T}$ & $\mathrm{T}$ & $T$ & $G$ & $\mathrm{~T}$ & $G$ & $\mathrm{~T}$ & $\mathrm{~T}$ & $\mathrm{~T}$ & $A$ & $A$ & $G$ & $G$ & C & $\mathrm{T}$ & A & $G$ & $\mathrm{G}$ & C & A & $\mathrm{T}$ & A & $\mathrm{G}$ & $\mathrm{T}$ & $\mathrm{G}$ & $G$ & \\
\hline CU40SD & C & $\mathrm{T}$ & A & $\mathrm{T}$ & $\mathrm{T}$ & $\mathrm{T}$ & $G$ & $\mathrm{~T}$ & $\mathrm{G}$ & $\mathrm{T}$ & $\mathrm{T}$ & $\mathrm{T}$ & $A$ & $A$ & G & $\mathrm{G}$ & C & $\mathrm{T}$ & A & G & G & C & A & $\mathrm{T}$ & A & $\mathrm{G}$ & $\mathrm{T}$ & $\mathrm{G}$ & $\mathrm{G}$ & \\
\hline CU10BB & C & $\mathrm{T}$ & A & $\mathrm{T}$ & $\mathrm{T}$ & $\mathrm{T}$ & $\mathrm{G}$ & $\mathrm{T}$ & $\mathrm{G}$ & $\mathrm{T}$ & $\mathrm{T}$ & $\mathrm{T}$ & $A$ & $A$ & G & $\mathrm{G}$ & C & $\mathrm{T}$ & A & G & G & C & A & $\mathrm{T}$ & A & $G$ & $\mathrm{~T}$ & G & $\mathrm{G}$ & \\
\hline CT23YG & C & $\mathrm{T}$ & A & $\mathrm{T}$ & $\mathrm{T}$ & $\mathrm{T}$ & $\mathrm{G}$ & $\mathrm{T}$ & $\mathrm{G}$ & $\mathrm{T}$ & $\mathrm{T}$ & $\mathrm{T}$ & $A$ & $A$ & G & G & C & $\mathrm{T}$ & A & G & $\mathrm{G}$ & C & A & $\mathrm{T}$ & A & $\mathrm{G}$ & $\mathrm{T}$ & $\mathrm{G}$ & $\mathrm{G}$ & \\
\hline CU09AP & C & $\mathrm{T}$ & A & $\mathrm{T}$ & $\mathrm{T}$ & $\mathrm{T}$ & $\mathrm{G}$ & $\mathrm{T}$ & $\mathrm{G}$ & $\mathrm{T}$ & $\mathrm{T}$ & $\mathrm{T}$ & $A$ & $A$ & $G$ & $\mathrm{G}$ & C & $\mathrm{T}$ & A & $G$ & G & C & A & $T$ & A & $\mathrm{G}$ & $\mathrm{T}$ & G & $\mathrm{G}$ & \\
\hline CT28BL & C & $\mathrm{T}$ & A & $\mathrm{T}$ & $\mathrm{T}$ & $\mathrm{T}$ & $\mathrm{G}$ & $\mathrm{T}$ & $\mathrm{G}$ & $\mathrm{T}$ & $\mathrm{T}$ & $\mathrm{T}$ & $A$ & $A$ & G & $\mathrm{G}$ & C & $\mathrm{T}$ & A & G & G & C & A & $\mathrm{T}$ & A & $\mathrm{G}$ & $\mathrm{T}$ & G & $\mathrm{G}$ & \\
\hline AK2/15 & C & $\mathrm{T}$ & A & $\mathrm{T}$ & $\mathrm{T}$ & $\mathrm{T}$ & $G$ & $\mathrm{~T}$ & $\mathrm{G}$ & $\mathrm{T}$ & $\mathrm{T}$ & $\mathrm{T}$ & $A$ & $A$ & G & $\mathrm{G}$ & C & $\mathrm{T}$ & A & $G$ & $\mathrm{G}$ & C & A & $\mathrm{T}$ & A & $\mathrm{G}$ & $\mathrm{T}$ & $\mathrm{G}$ & $G$ & \\
\hline AK & C & $\mathrm{T}$ & A & $\mathrm{T}$ & $\mathrm{T}$ & $T$ & $G$ & $\mathrm{~T}$ & $\mathrm{G}$ & $\mathrm{T}$ & $\mathrm{T}$ & $\mathrm{T}$ & A & $A$ & G & $\mathrm{G}$ & C & $\mathrm{T}$ & A & G & G & C & A & $\mathrm{T}$ & A & $\mathrm{G}$ & $\mathrm{T}$ & G & $\mathrm{G}$ & \\
\hline AK44BW & C & $\mathrm{T}$ & A & $\mathrm{T}$ & $\mathrm{T}$ & $\mathrm{T}$ & $G$ & $\mathrm{~T}$ & $\mathrm{G}$ & $\mathrm{T}$ & $\mathrm{T}$ & $\mathrm{T}$ & $A$ & $A$ & G & $G$ & C & $\mathrm{T}$ & A & $G$ & G & C & A & $\mathrm{T}$ & A & $G$ & $\mathrm{~T}$ & $G$ & $\mathrm{G}$ & \\
\hline
\end{tabular}

Gambar 1. Jajaran sekuen nucleotide $12 \mathrm{~S}$ rRNA mtDNA dari 16 individu rusa

Keterangan: $\mathrm{CU}=$ Cervus unicolor; $\mathrm{CT}=$ Cervus timorensis; $\mathrm{AK}=$ Axis kuhlii

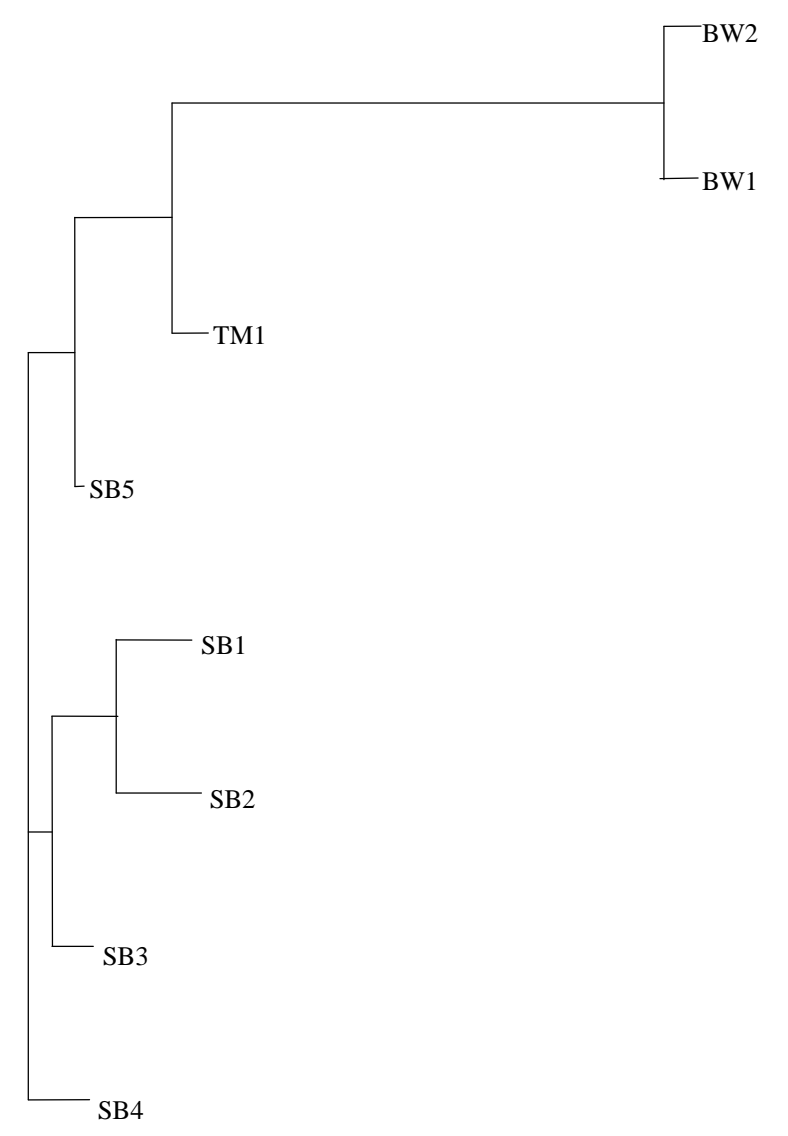

0.01

Gambar 2. Pohon filogeni dari sebaran Haplotipe dari masingmasing Jenis rusa. SB = haplotipe rusa Sambar; TM = haplotipe rusa Timor; BW = haplotipe rusa Bawean

\section{DAFTAR PUSTAKA}

Anderson R, 1984. Deer farming in Australia. Proceeding of deer refresher course. Refresher course for veterinarians. The post-graduate committee in Veterinary science (49): 55-71

Bemmel, van ACV, 1953. One of the rarest deer of the world. Beaufortia 27: 1-5

Brown WM, 1985. The Mitochondrial Genom of Animals in Molecular Evolutionary Genetic. Plenum Press, New York.

Brown GG, Gadaleta G, Pepe G, Saccone G, and Sbisa E, 1986. Structural conservation and variation in the D-loop containing region of vertebrate mitochondrial DNA. J. Mol. Biol. 192: 503-511

Cook EC, Ying Wang and George Sensabaugh, 1999. A Mitochondrial control region and cytochrome $b$ phylogeny of sika deer (Cervus nippon) and report of tandem repeats in the control region. Molecular Phylogenetics and Evolution 12(1): 47-56.

Felsenstein J, 1989. PHYLIP: Phylogeny Inference Package (Univ. Washington, Seattle).

Jeanmougin F, Thomson JD, Gouy M, Higgins DG, Gibson TJ, 1998. Multiple Sequence alingment with Clustal X. Trends Biochem Sci 23: 403-405.

Irwin DM, Kocher TD, and Wilson AC, (1991). Evolution of cytochrom $b$ gene of mammals. J. Mol. Evol. 32: 128-144.

Miyamoto MM, Kraus F, and Ryder OA, 1990. Phylogeny and evolution of antlered deer determined from mitochondrial DNA sequences. Proc. Natl. Acad. Sci. USA. 87: 6112-6131.

Moritz C, Dowling TE, and Brown WM, 1992. Evolution of Animal Mitochondrial DN. Relevance for population Biology and Systematics. Ann. Rev. Ecol. Syst. 18: 268292.

Randi E, Mucci N, Claro-Hergueta F, Bonnet A, and Douzery EJP, 2001. A mitochondrial DNA control region phylogeny of the Cervinae: speciation in Cervus and implication for conservation. Animal Conservation 4: 1-11. 
Semiadi G, 1993. The domestication and nutrition of sambar deer (Cervus unicolor): A comparative study with red deer (Cervus elaphus). PhD Dissertation. Massey University. Palmerston North. New Zealand.

Semiadi G, 2002. Upaya pembinaan penangkaran rusa sambar (Cervus unicolor) sebagai ternak baru dalam rangka pemberdayaan satwa liar berpotensi dan komoditas unggulan daerah Propinsi Kalimantan Timur. Laporan. Puslit Biologi LIPI.
Kocher TD, Thomas WK, Meyer A, Edwars SV, Paabo S, Villablanca FX, and Wilson AC, 1989. Dynamics of mtDNA evolution in animals: Amplification and sequencing with conserved primers. Proc Natl Acad Sci USA 86: 6196-6200.

Woodford KB and Dunning A, 1992. Production cycles and characteristics of rusa deer in Queensland, Australia. In: The Biology of deer (ed. RD Brown). Springer-Verlag, New York. 197-202.

Reviewer: Dr. Bambang Irawan, MSc. 